\title{
Uncertainties In The Effectiveness of Biological Control of Stem Borers Under Different Climate Change Scenarios In Eastern Africa
}

Ines Gwendolyn Jendritzki ( $\square$ ijendrit@uni-bonn.de )

Center for Development Research (ZEF), University of Bonn https://orcid.org/0000-0002-8602-8586

Henri E. Z. Tonnang

International Centre for Insect Physiology and Ecology

Paul-André Calatayud

Institut de recherche pour le développement: Institut de recherche pour le developpement

Christian Borgemeister

University of Bonn, Center for Development Research (ZEF)

Tino Johansson

Department of Geosciences and Geography, University of Helsinki

Lisa Biber-Freudenberger

University of Bonn, Center for Development Research (ZEF)

\section{Research Article}

Keywords: Kenya, Tanzania, stem borer pests, Integrated Pest Management, Species distribution modelling, Maxent

Posted Date: September 22nd, 2021

DOl: https://doi.org/10.21203/rs.3.rs-876884/v1

License: (9) This work is licensed under a Creative Commons Attribution 4.0 International License.

Read Full License 
1 Title: Uncertainties in the effectiveness of biological control of stem borers under different climate change scenarios in Eastern Africa

3

\section{$4 \quad$ Abstract}

5 Climate change (CC) is expected to significantly affect biodiversity and ecosystem services. Adverse impacts from CC in the Global South are likely to be exacerbated by limited capacities to take adequate adaptation measures and existing developmental challenges. Insect pests today are already causing considerable yield losses in agricultural crop production in East Africa. Studies have shown that insects are strongly responding to CC by proliferation, shift in distribution or by altering their phenology, which is why an impact on agriculture can also be expected. Biological control (BC) has been proposed as an alternative measure to sustainably contain insect pests but few studies predict its efficacy under future CC. Using the species distribution modelling approach Maxent, we predict the current and future distribution of three important lepidopteran stem borer pests of maize in eastern Africa, i.e., Busseola fusca (Fuller, 1901), Chilo partellus (Swinhoe, 1885) and Sesamia calamistis (Hampson, 1910), and two of their parasitoids that are currently used for BC, i.e., Cotesia flavipes (Cameron, 1891) and Cotesia sesamiae (Cameron, 1906). Based on these potential distributions and data collected during household surveys with local farmers in Kenya and Tanzania, future maize yield losses are predicted for a business-as-usual scenario and a sustainable development scenario. Accordingly, we found that BC of the three stem borer pests by $C$. flavipes and $C$. sesamiae will be less effective under more severe $C$ C resulting in a reduced ability to curb maize yield losses caused by the stem borers. These results highlight the need to adapt $\mathrm{BC}$ measures to future $\mathrm{CC}$ to maintain its potential for environmentally-friendly pest management strategies. The findings of this research are thus of particular relevance to policy makers, extension officers and farmers in the region and will aid the adaptation of smallholder agricultural practices to current and future impacts of CC. 


\section{Introduction}

Anthropogenic climate change (CC) will have substantial impacts on human-environment interactions, including the provisioning of important ecosystem services (IPCC, 2014). Countries in the Global South are predicted to be more exposed to the impacts of CC (Christensen et al., 2007), as they often lack the financial, institutional and human resources to cope with climatic and environmental change (Abeygunawardena et al., 2009). Many African countries are particularly vulnerable (WMO, 2019; Boko et al., 2007) and it is expected that the adverse effects of CC and environmental degradation will significantly constrain future economic and social development of the continent (AFDB et al., 2019; Baarsch et al., 2020; Boko et al., 2007) .

Kenya and Tanzania have achieved notable economic growth over the past decades (UN DESA, 2020; UNDP et al., 2018; World Bank, 2021), which has gradually translated into improved healthcare and education (World Bank, 2021). Agriculture continues to play an important role in many developing East African economies, and in particular in Kenya and Tanzania where the agricultural sector contributes significantly to national GDP and constitutes a major source of labor (ILO, 2021; Salami et al., 2010; World Bank, 2021). Still more than half of the working population works in the agricultural sector (World Bank, 2021). In East Africa, agricultural activity is dominated by smallholder farmers (Salami et al., 2010). Smallholder farmers hereby typically cultivate small plots and primarily produce for home consumption. They are highly vulnerable to external shocks, such as extreme weather events, pest and disease outbreaks or market fluctuations (Morton, 2007; Salami et al., 2010). Maize is an essential staple crop in sub-Saharan Africa (SSA) and the most important crop in Kenya and Tanzania (IITA, 2021; FAO, 2021a). In general, agricultural productivity in Africa remains significantly below the global average and is even lower than in other regions of the Global South (IFPRI, 2016; Salami et al., 2010). For instance, the average maize yield in East Africa was only 1.95 tonnes per hectare (t/ha) in 2019 (Kenya 1.77 t/ha and Tanzania $1.65 \mathrm{t} / \mathrm{ha}$ ) compared to the $5.8 \mathrm{t} / \mathrm{ha}$ globally (FAO, 2021a). Low agricultural productivity is one reason why food insecurity is still a major concern in the region (FAO et al., 2020). FAO data from 2019 reveals the dire situation in the region in terms of food (FAO et al., 2020). Despite some success in reducing undernourishment in the early 2000s, the figures have recently started to rise again and future projections of undernourishment in East Africa are worrisome such that Sustainable Development Goal (SDG) 2 by 2030 seems unlikely (FAO et al., 2020). An eminent threat to agricultural production and food systems is CC (FAO et al., 2020; IPCC, 2019; Thornton et al., 2014). Increasing climate variability, environmental degradation and the corresponding profound impacts on ecosystems will have direct effects on agricultural production and food security in East Africa and beyond (Anya et al., 2012; FAO et al., 2020; Sundström et al., 2014). Furthermore, the forecasted continued strong demographic growth in both countries will most likely exacerbate the situation (Thomas \& Zuberi, 2012; UN DESA Population Division, 2019).

Insect pests are damaging crops and may cause considerable yield losses (De Groote, 2002; Goftishu et al., 2017; Kfir et al., 2002; Oerke, 2006; Youdeowei, 1989). Recent studies show that pest insects are sensitive to temperature and strongly 
respond to CC (Ladányi \& Horváth, 2010; Lehmann et al., 2020; Mwalusepo et al., 2015; Stange \& Ayres, 2010) by altering their distribution, abundance and phenology (Biber-Freudenberger et al., 2016; Godefroid et al., 2020; Lehmann et al., 2020; Mwalusepo et al., 2015; Skendžić et al., 2021; Urvois et al., 2021). This will come with all the inherent consequences for agricultural production and food security in East Africa and other regions of SSA leading to new challenges for pest management (Biber-Freudenberger et al., 2016; Lehmann et al., 2020; Mwalusepo et al., 2015; Skendžić et al., 2021). The use of synthetic pesticides for crop protection has stagnated at a low level in SSA (FAO, 2021b). Across SSA, pesticide-based measures for pest control are of limited relevance to most smallholder farmers, which is mainly due to financial constraints, limited availability and lack of training (Kamau et al., 2018; Williamson et al., 2008). However, in response to current developments in many African countries that lead to rising income, a growing population, increasing food demand and changing dietary preferences, previously used traditional pest control methods are likely to be progressively replaced by application of synthetic pesticides (Schreinemachers \& Tipraqsa, 2012; Snyder et al., 2018). Though, smallholders are often not equipped with the necessary training to adequately and efficiently apply agrochemicals (Naidoo et al., 2010) and regulations on pesticide use are lenient (Haggblade et al., 2021; Karungi et al., 2011). Environmental and health concerns are an increasingly visible consequence of this development (Karungi et al., 2011; Negatu et al., 2021; Snyder et al., 2018; Tsimbiri et al., 2015).

Given that CC presumably impacts the distribution and spread of insect pests, it is likely that crop health and yields will also be affected. Hence, effective, sensible and anticipatory management and mitigation approaches are ever more important to minimize adverse impacts of $\mathrm{CC}$ on agricultural production. This will not only be essential when trying to build a resilient food system that can secure nutrition for the local population in the long-term, but also with regard to environmental degradation and the sustainable use of land resources. Integrated Pest Management (IPM), aiming at promoting healthy crops while minimizing disruptions to the environment and ecosystems (Barzman et al., 2015), can be an alternative or complementary approach to pesticide-based crop protection (Bale et al., 2008; Barzman et al., 2015). One approach in IPM is biological control (BC), a long-used and effective method in the prevention and containment of pest outbreaks, that uses biological agents to control harmful organisms (FAO, 2021c; Bale et al., 2008). Among the BC agents, larval parasitoid species have been reported to efficiently control open-field crop pests and are also largely used in the containment of stem borers (Bale et al., 2008; Cugala \& Omwega, 2001; Dejen et al., 2013). However, species' responses to CC differ (Ladányi \& Horváth, 2010) and established interactions of species used in BC programs may be disrupted (Mwalusepo et al., 2015; Skendžić et al., 2021; Thomson et al., 2010). Such climate-induced disruptions have the potential to render proven BC relationships ineffective (Thomson et al., 2010). Even though a number of studies are predicting the future distribution of pest species under CC (Lantschner et al., 2018), little is known about the impact of $\mathrm{CC}$ on the distribution of important $\mathrm{BC}$ agents. We therefore investigate the distribution of three maize borer species in 
Kenya and Tanzania in relation to the spread of their respective parasitoid $\mathrm{BC}$ agents used in the region to predict the future prevalence of these pests and the role of $\mathrm{BC}$ in reducing associated maize yield losses under different $\mathrm{CC}$ scenarios.

\section{Materials and methods}

\subsubsection{Species and presence records}

This study investigates the potential current and future habitat suitability and distribution of three important maize pests in East Africa, the lepidopteran stem borers Busseola fusca (Fuller), Sesamia calamistis (Hampson) (both Lepidoptera: Noctuidae), and Chilo partellus (Swinhoe) (Lepidoptera: Crambidae) (CABI, 2021a; De Groote, 2002; Kfir et al., 2002). B. fusca attacks different cereal crops, in particular maize and sorghum (CABI, 2021a; Kfir et al., 2002). It is native to Africa and widely established across the central, eastern and southern parts of the continent (CABI, 2021a). The invasive stem borer C. partellus, native to Asia (CABI, 2021a), is a major pest of maize, sorghum and pearl millet, but also infests other important crops (CABI, 2021a). It has a high adaptive capacity and tolerates a wide range of environmental conditions (CABI, 2021a; Mutamiswa et al., 2017). Hence, C. partellus is a competitive colonizer, that now is widely present across Africa, and has been reported to increasingly dominate and displace certain native African stem borer species (CABI, 2021a; Mutamiswa et al., 2017; Kfir et al., 2002). S. calamistis attacks maize, sorghum, pearl millet, rice, wheat and sugarcane (CABI, 2021a). Indigenous to Africa, it is widely distributed throughout 33 countries in SSA (CABI, 2021a). Despite its presence in East Africa, S. calamistis is of less importance there to maize production than B. fusca and C. partellus (Cugala \& Omwega, 2001; Nsami et al., 2001; Tamiru et al., 2007).

We additionally predict the potential distribution of two important $\mathrm{BC}$ agents of stem borers, the gregarious larval endoparasitoids Cotesia sesamiae (Hampson) and Cotesia flavipes (Hampson) (both Hymenoptera: Braconidae) (CABI, 2021b). The two parasitoids are strategically used as BC agents of stem borer pests in South, Central and East Africa (Dejen et al., 2013; Kaiser et al., 2017; Overholt et al., 1997). Being native to Pakistan (CABI, 2021b), C. flavipes has been introduced in Kenya in 1993 as part of a BC program of $C$. partellus (Kfir et al., 2002; Omwega et al., 2006). Since, then, use of the paraistoid has been successful in controlling the spread of stem borers in many countries of SSA (Kaiser et al., 2017; Overholt et al., 1997). C. flavipes attacks a broad range of insect pests (CABI, 2021b), including $B$. fusca and S. calamistis. The endoparasitoid C. sesamiae is indigenous to Africa, widely distributed across SSA with only few proven records outside the continent (CABI, 2021b). Even though $C$. sesamiae is less frequently used in BC programs, it can effectively suppress the spread of different lepidopteran pests, including C. partellus, B. fusca and S. calamistis (CABI, 2021b; Kaiser et al., 2017).

Presence records for the five species (B. fusca: 477, C. partellus: 251, S. calamistis: 260, C. flavipes: 190, C. sesamiae: 190) were obtained from several sources, reflecting different levels of extent and intensity of sampling efforts. Central to our research were data from a 2018 household survey conducted by researchers from the International Centre of Insect 
Physiology and Ecology (icipe) under the cooperative project "Adaptation for Food Security and Ecosystem Resilience in Africa" (AFERIA) of icipe, the University of Helsinki and the University of York. The coordinates of the surveyed households that reported species presence were used for the Species Distribution Modelling (SDM) exercise in this study. These data were complemented by occurrence points downloaded from the Global Biodiversity Information Facility (GBIF) and data obtained from icipe's the "Climate Change Impacts on Ecosystem Services and Food Security in Eastern Africa" (CHIESA) project that was implemented between 2011 and 2015. Additional presence points emanated from icipe's "Integrated pest management strategy to counter the threat of invasive fall armyworm to food security in eastern Africa” (FAW-IPM) project.

\subsubsection{Environmental variables}

All environmental variables used for the SDM were downloaded in 2.5 arc minutes resolution from WorldClim version 2.1 [Coupled Model Intercomparison Project Phase 6 (CMIP6)] (Fick \& Hijmans, 2017). WorldClim provides data for 19 bioclimatic variables frequently used in SDM, which are derived from temperature and rainfall data and hence constitute biologically meaningful indicators for species distribution. The bioclimatic variables consider annual averages, extreme values and seasonality (Fick \& Hijmans, 2017). Global data for the bioclimatic variables is available for past, present and future climate scenarios (Fick \& Hijmans, 2017). Current bioclimatic variables are based on the averages of the years 1970-2000, whereas future bioclimatic variables are derived from extrapolations and comprise the averages of the 20-year periods 2021-2040, 2041-2060, 2061-2080 and 2081-2100 (Fick \& Hijmans, 2017). Future bioclimatic data is available for different General Circulation Models (GCMs) and four Shared Socioeconomic Pathways (SSPs). Since the distribution of stem borers is altitude-dependent (Cugala \& Omwega, 2001; Mwalusepo et al., 2015), elevation was included as an additional environmental variable in this study. Elevation data was also retrieved from WorldClim and is based on Shuttle Radar Topography Mission (SRTM) elevation data (Fick \& Hijmans, 2017). For a description of the environmental variables used for modelling check the supplementary materials.

For the projection of the SDM onto future climatic conditions, the bioclimatic variables were downloaded for three selected GCMs (CanESM5, CNRM-CM6-1 and MIROC6) that have been found to appropriately describe future climate in East Africa. The four SSPs describe different trajectories in future global development that entail different degrees of CC adaptation and mitigation. The SSPs are furthermore linked to distinct Representative Concentration Pathways (RCPs) that determine the levels of radiative forcing that are associated with the development trajectories and largely determine the intensity of CC. Accordingly, SSP1-2.6 represents an optimistic narrative of sustainable future global development, while SSP5-8.5 illustrates the worst-case emission scenario that neglects CC adaptation and will require extensive mitigation measures (Riahi et al., 2016). Given that an insight into both, the nearer future and longer-term climatic conditions, are relevant for farmers in the region, the periods 2041-2060 and 2081-2100 were considered. 


\subsubsection{Distribution modelling approach}

The open source software Maxent for modelling species niches and distributions is one of the most popular tools used among experts. We modelled the species distribution with Maxent using the 'kuenm' package in R (Cobos et al., 2019). Maxent applies a machine-learning technique for maximum entropy modelling (Phillips et al., 2006). It uses a collection of georeferenced presence-only records of a species and a set of relevant environmental variables (Phillips et al., 2006). Maxent builds a model based on the distribution of maximum entropy and a set of constraints provided by the environmental variables that predicts habitat suitability for each grid cell (Phillips et al., 2006). Each cell in the study area is therewith assigned a probability value between 0 and 1 that categorizes habitat suitability, with 0 indicating no habitat suitability and 1 marking cells that provide a perfectly suitable habitat (Phillips et al., 2006). Maxent furthermore allows to project habitat suitability onto new environments in space and time (Elith et al., 2010). The projection into different geographical settings might reveal habitats where a species has not been recorded yet, whereas projection in time can provide information on the potential distribution of species in the past or future, which is of particular relevance in predicting the potential effects of CC on species (Franklin, 2010). For projecting species distribution onto new environments, the model is trained based on a sample of presence-only points and current data of selected environmental variables. Based on additional environmental data that characterize habitats in different geographic areas, or represent past or future environmental conditions, the model of the current distribution can be used to forecast habitat suitability elsewhere or under future environmental conditions, respectively (Phillips, 2017).

In this study, we model the species' potential current and future distribution. By including three GCMs from CMIP6 we account for the inherent uncertainties of climate projection modelling (Beaumont et al., 2008). Future habitat suitability constitutes an ensemble average across several GCMs that was obtained by calculating mean suitability rasters according to SSP and time period. The suitability maps were then converted into species distribution maps by application of four selected suitability threshold levels. For each CC scenario according to SSP and time period, three habitat suitability maps were calculated, one for each GCM. For each habitat suitability map, four threshold levels were applied to categorize species presence or absence. As a result, 12 distribution maps were available per scenario and species, which were then stacked and calculated in their sum to show areas where, based on the different GCMs and thresholds, presence of the species is more or less likely.

\subsubsection{Estimation of yield loss and BC efficacy}

Using the distribution data of the three stem borer species, associated maize yield losses were calculated. Data on maize yields in the study region were downloaded from the MapSPAM data center (IFPRI, 2020) (see supplementary materials). Maize yield losses in the study area were quantified via data from the AFERIA household survey. A total sample of 225 household was surveyed out of which 208 households reported maize yield losses by S. calamistis, and 206 and 197 by 
B. fusca and C. Partellus, respectively. The respondents were furthermore asked to quantify the yield losses by stem borers in percent. Based on these survey data, we calculated $95 \%$ confidence intervals (CIs) for maize yield losses, which were then used to project current and future losses by stem borers. We predicted areas with high probability of maize yield losses by stem borers by multiplying species distribution maps with a raster carrying values on maize yields and a raster of yield losses caused by them (Equ.1). Consequently, grid cells, where the stem borers are predicted to be present and the cultivation of maize overlap are identified as areas with potential yield losses by the pests.

$$
Y_{c, p}=A_{c, p} * M_{c} * L_{p}
$$

(Equation 1)

where $Y_{c, p}$ represents yield losses $(\mathrm{kg} / \mathrm{ha})$ for each grid cell $c$ and each stem borer species $p, A_{c, p}=\{1,0\}$ indicates each stem borer species' presence or absence for each grid cell, $M_{c}$ indicates maize yield $(\mathrm{kg} / \mathrm{ha})$ for each cell and $L_{p}$ representing estimated yield losses by each stem borer (\%). Furthermore, we predicted the current and future potential of using the parasitoids $C$. flavipes and $C$. sesamiae to control the pests and thereby reduce maize yield losses. As part of the AFERIA household survey respondents were asked for the potential of using the parasitoids to reduce maize yield losses caused by the respective stem borer species. Reduction potential was ranked by the respondents according to three different rank categories with rank 1: low (0-25\%), rank 2: medium (25-75\%) and rank 3: high (75-100\%). For the calculation of the reduction potential, we used the mean value for each of the ranks, i.e., rank 1: $12.5 \%$, rank $2: 50 \%$ and rank 3: $87.5 \%$. We calculated the $95 \%$ CI on maize yield loss reduction to project current and future loss reduction potential by the two parasitoid species. We furthermore calculated the potential reduction of maize yield losses when using $C$. flavipes and $C$. sesamiae by multiplying the binary range maps of the natural enemy species with the maize yield loss and the reduction potential (Equ.2). Accordingly, areas where presence of each parasitoid species overlaps with areas where maize yield losses by the stem borer pests occur were identified and yield loss reduction was calculated as follows:

$$
R_{c, e}=B_{c, e} * Y_{c, p} * P_{e}
$$

where $R_{c, e}$ represents the potential reduction of yield losses $(\mathrm{kg} / \mathrm{ha})$ for each grid cell $c$ by natural enemy $e, B_{c, e}=\{1,0\}$ indicates parasitoid presence or absence for each grid cell, $Y_{c, p}$ indicates maize yield losses $(\mathrm{kg} / \mathrm{ha})$ and $P_{e}$ represents estimated potential yield losses reduction by the parasitoids (\%).

\subsubsection{Sampling bias}

The presence points used for this research have to a large extent been collected within the scope of studies conducted in Kenya and Tanzania. However, it is not known whether the concentration of presence records can be attributed to more favorable environmental conditions and hence greater habitat suitability for the species, or whether this agglomeration of 
presence points might be due to greater sampling efforts. Geographical bias of occurrence data may, however, result in low quality models (Phillips et al., 2009) and incorrect predictions of species distribution (Fourcade et al., 2014). In order to account for the potentially misleading uneven geographical distribution of the presence records used in SDM, a bias file was constructed. A sample of more than 700,000 presence coordinates of different insect species (Phillips et al., 2009) recorded on the African continent was downloaded from GBIF. Based on these records, a kernel density estimate map was constructed using the 'MASS' package in R and used to correct for potential sampling bias in the modelling process (compare Biber-Freudenberger et al., 2016; Fourcade et al., 2014).

\subsubsection{Model calibration and best model selection}

Apart from the inputs required to run Maxent, a wide variety of parameter settings can be individually adjusted by the user to build the best-performing model. For almost all parameters in-built default settings have been validated by the developers of the software over a wide range of models. However, Morales et al. (2017) and Merow et al. (2013) indicate that the adoption of Maxent's default settings may not necessarily produce the optimal model to predict species distribution. According to Radosavljevic and Anderson (2014) the individual tuning of setting parameters for each species the 'kuenm' package in R (Cobos et al., 2019) that allows for automated detailed model calibration and hence robust selection of the best-performing model (Cobos et al., 2019). Accordingly, for each species 279 models were calibrated using different sets of environmental variables (Set1: 19 bioclimatic variables and elevation, Set2: BIO1, BIO5, BIO6, BIO12, BIO13, BIO14, elevation, Set3: BIO5, BIO6, BIO13, BIO14, elevation), values for the regularization multiplier $(0.1,1$ and 10) and multiple combinations of feature classes (linear (l), product (p), quadratic (q), hinge (h), threshold (t)). For all tested models a random sample of $66.6 \%$ of presence localities was used as training data for building the models. The remaining $33.3 \%$ of the presence records was set aside for testing the models. The combination of parameters yielding the best-performing model for each species was selected considering statistical significance [partial Receiver Operating

\section{Results}

\subsection{Habitat suitability under current and future climatic conditions}

250 The mean Area under the ROC Curve (AUC) values of training data for all five species over 15 replicate models runs are 
The probability of habitat suitability was modelled for each species for current climatic conditions and different CC scenarios. Current habitat suitability in the study area and predicted future suitability for the period 2081-2100 are shown in Fig. 1. The optimistic scenario SSP1-2.6 that describes sustainable global development with low challenges in mitigation and adaption is contrasted with the worst-case scenario SSP5-8.5 to demonstrate the changes in suitable habitats according to two opposing scenario pathways (results for SSP2-4.5 and SSP3-7.0, as well as for all scenarios in 2041-2060 available in supplementary materials). Under current climatic conditions, high suitability for $B$. fusca is predicted in the border areas of Kenya and Tanzania but is forecasted to decline under both projected pathway scenarios. While under SSP1-2.6 habitat suitability is predicted to decrease only in areas with currently very high suitability, in scenario SSP5-8.5 habitat suitability declines at a significantly higher rate and across the whole study region. Regions that are now highly suitable are predicted to become largely unsuitable for the stem borer under this scenario. It is therefore to be expected, that under more severe CC the associated changes in habitat suitability will have considerable adverse effects on B. fusca. A similar observation can be made from the projections of habitat suitability for S. calamistis. At present, the border regions of both countries show relatively high habitat suitability, which is predicted to decline in the future under both SSPs. However, in case of SSP5-8.5 the decline in habitat suitability is dramatic for the period 20812100, indicating that habitat, which is currently highly suitable, will become largely unsuitable. Furthermore, overall habitat suitability in the study area will decrease remarkably and areas providing suitable habitats for S. calamistis will be restricted to only a few scattered localities. Current and predicted future habitat suitability for B. fusca and S. calamistis is noticeably lower than for the invasive C. partellus, reflecting the greater tolerance for a wide range of environmental conditions and high adaptability of the latter species that also facilitates its successful invasion into new environments. Current probability of habitat suitability for $C$. partellus is high to very high across large areas of the study region. Yet also this invasive stem borer is predicted to be impacted by changing future climate under the shown SSPs. While for SSP1-2.6 areas with very high habitat suitability are forecasted to slightly decrease, these are predicted to be considerably reduced under scenario SSP5-8.5. Hence, also for $C$. partellus habitat suitability is likely to be more adversely impacted under more severe CC. Habitat suitability for the natural enemies $C$. flavipes and $C$. sesamiae is also predicted to decline in the future under both SSPs. This decline is, however, less pronounced under SSP1-2.6. Areas of currently very high suitability for $C$. flavipes will shrink. For SSP5-8.5 in 2081-2100 areas that are highly suitable at present will become unsuitable, while regions of medium suitability will establish in northwestern Kenya. Currently there is only limited habitat suitability for the native $C$. sesamiae concentrating in the border region of Kenya and Tanzania. However, suitability is predicted to further decline for the considered time period and both SSPs. Under the pessimistic scenario SSP5-8.5 only a few scattered regions of medium suitability will remain. Accordingly, under severe CC large parts of the study region are predicted to become unsuitable for $C$. sesamiae. Furthermore, habitat suitability for the native species $B$. 
fusca, S. calamistis and C. sesamiae will be more adversely impacted by severe CC than for the non-native ones, i.e., $C$. partellus and C. flavipes.

Fig. 1 Probability of habitat suitability under current climatic conditions and in 2081-2100 for SSP1-2.6 and SSP5-8.5 calculated as multi-model average from GCMs CanESM5, CNRM-CM6-1 and MIROC6. Probability of habitat suitability ranges between 0 (low probability of suitable habitat) and 1 (perfectly suitable habitat). Grid cells with great suitability carry high probability values and are displayed in dark red, whereas cells with low suitability show low probability values and are colored in lighter red and white

In this study different suitability threshold levels were selected (Balance training omission, predicted area and threshold values Cloglog threshold (thereafter bto), Maximum training sensitivity plus specificity Cloglog threshold (mtss), Equal training sensitivity and specificity Cloglog threshold (etss), $10^{\text {th }}$ percentile training presence Cloglog threshold (tp)) to convert habitat suitability maps into binary species range maps (for specific values see supplementary materials). Selection of several threshold values has advantages over application of a single threshold, as it considers the inherent uncertainties.

The potential distribution of the stem borer and parasitoid species under current climatic conditions, as well as for the CC scenarios SSP1-2.6 and SSP5-8.5 in 2081-2100 varies significantly (Fig. 2). Among the stem borers the invasive $C$. partellus is predicted to be currently most widely distributed, whereas distribution of the native stem borers concentrates around the border area of the study region. The modelled current distribution of the parasitoids is less widespread than for the stem borers. Under future CC the distribution of all five species is predicted to slightly shift or decrease for SSP12.6. Areas that currently show high likelihood of species presence are less likely to inhabit them in the future. For SSP58.5 a significant reduction in the distribution of all five species is forecasted. Under the worst-case scenario, C. sesamiae becomes extremely rare in the study region, while the distribution of $C$. flavipes will shift towards northwestern Kenya. The predicted presence of the stem borer species is reduced across the entire study area

Fig. 2 Sum of 4 binary range maps (current distribution) and 12 binary range maps (future distribution) obtained by application of 4 threshold levels, with each binary layer showing either species presence (1) or absence (0). Predicted species distribution under current climatic conditions and for pathways SSP1-2.6 and SSP5-8.5 for period 2081-2100. Grid cells where predicted species presence is likely are colored in red and orange, whereas grid cells where presence is 


\subsection{Pest impact on maize yields}

We calculated $95 \%$ CIs of maize yield losses for each stem borer based on the household survey data. With an average loss of $28.72 \%$, [95\% CI 26.65, 30.79], yield losses by C. partellus are highest, followed by B. fusca with an average loss of $27.86 \%$, [95 \% CI 25.77, 29.96], and S. calamistis with 27.25\%, [95\% CI 24.9, 29.59]. Predicted mean current and future yield losses by the three stem borers shown as mean value and for suitability threshold level bto (Fig. 3) (for minimum and maximum losses, as well as losses for SSP2-4.5 and SSP3-7.0, time period 2041-2060 and thresholds mtss, etss and tp see supplementary materials). Compared to current levels, maize losses are predicted to slightly decrease for B. fusca in SSP1-2.6, while remaining relatively stable for C. partellus and S. calamistis. Yield losses by all three species are predicted to decrease significantly until 2081-2100 under pathway SSP5-8.5. This decrease can be attributed to the notable decline in habitat suitability (Fig. 1), which is projected to result in reduced future species presence in the study area (Fig. 2). Hence, maize yield losses associated with the stem borer species are expected to decline under more severe CC, while remaining at a higher level for SSP1-2.6. Nevertheless, the degree of yield losses largely depends of the suitability threshold applied (see supplementary materials), with bto showing a remarkably larger area of predicted yield losses.

Fig. 3 Predicted mean maize yield losses (in $\mathrm{kg} / \mathrm{ha}$ ) by the stem borers B. fusca, C. partellus and S. calamistis under current climatic conditions and in 2081-2100 for SSP1-2.6 and SSP5-8.5 for suitability threshold bto. Grid cells with high predicted yield losses are colored in darker orange to brown, whereas cells where maize yield losses by the species are low are colored in lighter orange and white

\subsection{Future role of $\mathrm{BC}$ in reducing maize yield losses by stem borers}

Based on the household survey data, $C$. flavipes is with $53.68 \%$ [95\% CI 50.2, 57.16], slightly more effective than $C$. sesamiae with $51.39 \%$ [95\% CI 47.84, 54.93] in reducing yield losses by stem borers. The potential of using the natural enemies $C$. flavipes and $C$. sesamiae to reduce maize yield losses caused by the stem borer species varies depending on the two scenarios SSP1-2.6 and SSP5-8.5 in 2081-2100 (Figs. 4 and 5) (for minimum and maximum reduction potential, as well as possible reduction of yield losses by BC for SSP2-4.5 and SSP3-7.0, time period 2041-2060 and thresholds mtss, etss and tp see supplementary materials). In general, $C$. flavipes has a greater potential to reduce $B$. fusca maize yield losses than $C$. sesamiae. Yet, its potential to reduce losses by $B$. fusca is predicted to decline for both developmental pathways, especially in SSP5-8.5. Furthermore, $C$. flavipes is predicted to be more effective in reducing maize yield losses caused by the invasive $C$. partellus than $C$. sesamiae. For both $\mathrm{BC}$ agents the potential to reduce maize yield losses by $C$. partellus is predicted to decline. Whereas SSP1-2.6 entails a less significant decrease, the worst-case scenario SSP5-8.5 is predicted to result in a remarkably lower reduction potential. The same is true for containing maize yield losses caused 
by $S$. calamistis; here also C. flavipes shows a higher reduction potential. However, areas in which stem borer-caused maize yield losses can be reduced by BC with the two parasitoids are predicted to decline under the studied CC scenarios. While the reduction potential by $C$. flavipes is predicted to be significantly reduced under SSP5-8.5, the BC potential of C. sesamiae will have almost entirely vanished under that scenario. Analysing the predictions for the future effectiveness of using the two natural enemy species to reduce maize yield losses by the three stem borers in the study region, we therefore conclude that the more severe $\mathrm{CC}$ will be, the bigger is the decrease in the $\mathrm{BC}$ reduction potential of the two Cotesia species.

Fig. 4 Predicted mean reduction of maize yield losses (in kg/ha) by B. fusca, C. partellus and S. calamistis through use of $C$. flavipes under current climatic conditions and in 2081-2100 for SSP1-2.6 and SSP5-8.5 for suitability threshold bto. Grid cells where parasitoid application significantly reduces the amount of maize yield losses caused by the stem borer are colored in darker green, whereas cells with lower predicted reduction of maize yield losses are colored in lighter green and white

Fig. 5 Predicted mean reduction of maize yield losses (in $\mathrm{kg} / \mathrm{ha}$ ) by B. fusca, C. partellus and S. calamistis through use of C. sesamiae under current climatic conditions and in 2081-2100 for SSP1-2.6 and SSP5-8.5 for suitability threshold bto. Grid cells where parasitoid application significantly reduces the amount of maize yield losses caused by the stem borer are colored in darker green, whereas cells with lower predicted reduction of maize yield losses are colored in lighter

\section{Discussion and conclusions}

The three studied maize stem borers and their two associated larval parasitoids are very likely to respond to CC, regardless of the respective change scenario. The uncertainties inherent when making predictions on future climate and environmental conditions were considered by investigating species distribution using different CC models, socioeconomic pathways and time periods. Under all investigated CC scenarios habitat suitability is going to change and the species are predicted to adjust their distribution. We also found that all species' future distribution strongly depends on the magnitude of CC. More severe CC is predicted to cause a notable decrease in the presence of the stem borers, which will result in a decline in predicted maize yield losses associated with the pests. This decline in yield losses is, however, predicted to be accompanied by a decreasing potential to reduce losses caused by stem borers through the use of $C$. flavipes and C. sesamiae. The distribution of the two natural enemies is forecasted to significantly decline under severe CC, which may render established mechanisms of BC ineffective or not viable. This finding is of direct relevance 
to farmers in the study area that control stem borers with the parasitoids, as they will likely need to adjust their pest management strategies in the future.

For the calculation of maize yield losses, we assumed that the maize yield in the study area remains constant over time. Yet, the possible introduction of improved crop varieties with higher resilience to climate variability and attack by stem borers, the emergence of higher-yielding varieties or changes in productivity could affect future yields (Bänziger et al., 2006; IFPRI, 2016). We also did not consider the impact of CC on maize plants and yields themselves and assume that the geographic distribution of maize cultivation and yields remains constant over time, despite changing environmental conditions. Though, maize plants will be affected by $\mathrm{CC}$ and consequently the suitability of certain regions in Africa for maize production might change (Tito et al., 2018). This may eliminate maize cultivation in some areas while enabling it in others (Jones \& Thornton, 2003; Luhunga, 2017). The potential shift in habitat suitability for maize may create new overlaps with the distribution of pests and parasitoids, which in turn impacts yields, yield losses and opportunities for BC. When investigating the impact of $\mathrm{CC}$ on pests and agricultural crops, it is also important to determine how climate variability affects the crop species. Moreover, stem borers not only damage maize but a whole range of cereal crops (CABI, 2021a). Considering the potential impact of stem borers on food security, it would therefore be of great interesting to investigate their relevance for other important staple crops, in particular sorghum and millet whose cultivation in the region is currently pushed forward as of greater drought resilience (Burke et al., 2009; CSIRO, 2021; IFAD, 2017).

Other studies have also assessed the potential future distribution of pests and other species under future CC. Our findings are in line with Thomson et al. (2010) outlining that CC influences interactions between herbivores and natural enemies, e.g. by resulting in a mismatch in their distribution, which can reduce the effectiveness of using natural enemies for pest control. Mwalusepo et al. (2015) investigated the impact of temperature change on the future distribution of maize stem borers and their BC agents at a local scale along Mount Kilimanjaro and the Taita Hills of Tanzania and estimated the impact on maize yields. They confirm that temperature is a key factor in determining the distribution of stem borer pests and their natural enemies, corroborating results from our study. Yet, Mwalusepo et al. (2015) predict a worsening of pest impact on maize production along the two mountain gradients, whereas we forecast, especially for the more distant future (2081-2100), stem borer-associated maize yield losses to decline under the impact of more severe CC. Furthermore, Mwalusepo et al. (2015) predict a geographical disruption in the distribution of stem borers and their natural enemies, with decreased but also increased levels of $\mathrm{BC}$ at higher and lower altitudes, respectively. In contrast, we conclude that the studied BC relationships will become less effective and even unviable under future CC. The discrepancies in the findings of our study and the research by Mwalusepo et al. (2015) stem from the different modelling approaches applied and inputs used. Mwalusepo et al. (2015) predict species distribution based on temperature-driven phenology models, whereas our research employs a correlative method for SDM that uses maximum entropy density estimations. One advantage of the latter method is that it allows to incorporate the range in potential modelling outputs by assigning habitat 
suitability as a probability value, thereby also considering uncertainty. Furthermore, Mwalusepo et al. (2015) analyze potential future species distribution according to different levels of altitude in the study area. Our study, however, included elevation as homologous to the bioclimatic variables into model calibration and does not distinguish modelling outputs based on elevation but draws conclusions on country level. Dynamically downscaled Regional Climate Models (RCMs), as used by Mwalusepo et al. (2015), provide data at a finer resolution and capture mesoclimatic dynamics more accurately which potentially results in better simulations of regional climate than coarse resolution GCMs (Beaumont et al., 2008; Giorgi, 2019). In our study, we explicitly used data for the bioclimatic variables in 2.5 arc minutes resolution which is based on the latest version of GCMs from CMIP6. This approach is reasonable when examining the effects of climatic changes, i.e., changes in temperature and precipitation, on species distribution.

We focused our study at three stem borer pests and two important natural enemy species. The emergence of new pests or BC agents as a result of CC was not part of this study. For instance the 2016 introduction into Africa and subsequent wide spread of the neotropical fall armyworm (FAW), Spodoptera frugiperda (J.E. Smith) (Lepidoptera: Noctuidae) (Goergen et al., 2016) initially lead to spectacular increases in maize losses and near suppression of all other lepidopteran stem borer species in the FAW affected countries (Hailu et al., 2021; Sokame et al., 2021). This new pest will probably also modify the expected changes in the distribution and abundance of the here modelled stem borers and their parasitoids. Such developments pose new challenges for pest management that will, among others, require the adaption of BC strategies. It is hence of great interest to investigate the distribution of a broader range of pests and their natural enemies to obtain a more holistic picture on relevant insect pests, their impact on staple crop production and the potential of BC to be able to offer more concrete advice to farmers (Biber-Freudenberger et al., 2016). We found that the invasive stem borer $C$. partellus and the exotic parasitoid $C$. flavipes are and will be more widely distributed under CC, indicating that they are less prone to $\mathrm{CC}$. Hence, research on invasive pests and possibilities for their containment, e.g., via BC, needs to be intensified. For that, modelling could be indefinitely repeated using presence data for all organisms of interest. Given the low agricultural productivity in the region and the prevailing deficiencies in the food system (IFPRI, 2016), we demonstrate that maize stem borers are and to a certain extend will continue to be a threat to food security in the future. Therefore, effective control measures need to be applied to mitigate their proliferation and reduce associated yield losses. Empowering relevant actors to anticipate changes in insect distribution triggered by $\mathrm{CC}$ will be essential in building a more resilient food system that is less prone to external shocks (Bottrell \& Schoenly, 2018).

We believe our results to be of high relevance for farmers, extension officers and policy makers in Kenya and Tanzania, as they provide estimations not only of future pest distributions, but also of associated yield losses and the potential of $\mathrm{BC}$ to contain these pests. Hence, this study can serve as a blueprint to identify future pests as well as their potential natural enemies in East Africa and beyond, which will help farmers to adjust their farming and pest management strategies to changing environmental conditions. As anticipatory and effective pest management is fundamental in reducing yield 
losses, policy makers and extension officers could support farmers in adapting their practices to increase the resilience of local agricultural systems. To our knowledge this is one of very few studies that combines the prediction of future pest species distribution with the potential of BC under different CC scenarios while also considering the impact on maize, which is the most relevant crop in the study area. Pesticide-based pest control measures are increasing in importance; however, sustainable methods of pest control need to be promoted to avoid adverse impacts on health and the environment. The examined BC relationships have been proven effective at present, but we forecasted that their potential under future $\mathrm{CC}$ will substantially decline. Assuring the continued efficacy of $\mathrm{BC}$ to avoid dis-adoption, increasing skepticism among farmers and turn towards synthetic pesticides, is key in building a sustainable and environmentallyfriendly food system. We therefore suggest an increasing consideration of pest species as well as the potential of different BC strategies under varying environmental and climatic conditions.

\section{Supplementary materials}

1) Presence records

2) Overview presence records and sources

3) Distribution of species' presence points used for modelling

4) Description of environmental variables

5) Overview of best-performing calibrated models

6) Summary of mean of training AUC of best-performing model

7) Contribution of environmental variables to the models

8) Habitat suitability maps for all scenarios

9) Overview of suitability thresholds applied and their specific values

10) Distribution maps for all scenarios

11) Maize yields in the study area

12) Maize yield losses caused by stem borers, all scenarios

13) Potential of $\mathrm{BC}$ to reduce maize yield losses by stem borers, all scenarios

\section{References}

Abeygunawardena, P., Vyas, Y., Knill, P., Foy, T., Harrold, M., Steele, P., Tanner, T., Hirsch, D., Oosterman, M., Rooimans, J., Debois, M., Lamin, M., Liptow, H., Mausolf, E., Verheyen, R., Agrawala, S., Caspary, G., Paris, R., Kashyap, A., ... Sperling, F. (2009). Poverty and Climate Change: Reducing the Vulnerability of the Poor through Adaptation. http://documents.worldbank.org/curated/en/534871468155709473/Poverty-and-climatechange-reducing-the-vulnerability-of-the-poor-through-adaptation 
African Development Bank (AFDB) Group, UNEP, \& UNECA. (2019). Climate Change Impacts on Africa's Economic Growth.

Anya, M. I., Ofem, N. I., Binang, W. B., \& Umoren, E. P. (2012). Climate Change and Food Security in Africa. Asian Journal of Agricultural Research, 6(2), 52-59. https://doi.org/10.3923/ajar.2012.52.59

Baarsch, F., Granadillos, J. R., Hare, W., Knaus, M., Krapp, M., M., S., \& Lotze-Campen, H. (2020). The impact of climate change on incomes and convergence in Africa. World Development, 126. https://doi.org/https://doi.org/10.1016/j.worlddev.2019.104699

Bale, J. S., Van Lenteren, J. C., \& Bigler, F. (2008). Biological control and sustainable food production. Philosophical Transactions of the Royal Society B: Biological Sciences, 363, 761-776. https://doi.org/10.1098/rstb.2007.2182

Bänziger, M., Setimela, P. S., Hodson, D., \& Vivek, B. (2006). Breeding for improved abiotic stress tolerance in maize adapted to southern Africa. Agricultural Water Management, 80, 212-224. https://doi.org/10.1016/j.agwat.2005.07.014

Barzman, M., Bàrberi, P., Birch, A. N. E., Boonekamp, P., Dachbrodt-Saaydeh, S., Graf, B., Hommel, B., Jensen, J. E., Kiss, J., Kudsk, P., Lamichhane, J. R., Messéan, A., Moonen, A. C., Ratnadass, A., Ricci, P., Sarah, J. L., \& Sattin, M. (2015). Eight principles of integrated pest management. Agronomy for Sustainable Development, 35(4), 1199-1215. https://doi.org/10.1007/s13593-015-0327-9

Beaumont, L. J., Hughes, L., \& Pitman, A. J. (2008). Why is the choice of future climate scenarios for species distribution modelling important? Ecology Letters, 11(11), 1135-1146. https://doi.org/10.1111/j.14610248.2008.01231.x

Biber-Freudenberger, L., Ziemacki, J., Tonnang, H. E. Z., \& Borgemeister, C. (2016). Future risks of pest species under changing climatic conditions. PLoS ONE, 11(4). https://doi.org/10.1371/journal.pone.0153237

Boko, M., Niang, I., Nyong, A., Vogel, C., Githeko, A., Medany, M., Osman-Elasha, B., Tabo, R., \& Yanda, P. (2007). Africa. Climate Change 2007: Impacts, Adaptation and Vulnerability. Contribution of Working Group II to the Fourth Assessment Report of the Intergovernmental Panel on Climate Change (M. L. Parry, O. F. Canziani, J. P. Palutikof, P. J. van der Linden, \& C. E. Hanson (eds.); pp. 433-467). Cambridge University Press.

Bottrell, D. G., \& Schoenly, K. G. (2018). Integrated pest management for resource-limited farmers: Challenges for achieving ecological, social and economic sustainability. The Journal of Agricultural Science, 156, 408-426. https://doi.org/10.1017/S0021859618000473 
Burke, M. B., Lobell, D. B., \& Guarino, L. (2009). Shifts in African crop climates by 2050, and the implications for crop improvement and genetic resources conservation. Global Environmental Change, 19(3), 317-325. https://doi.org/10.1016/j.gloenvcha.2009.04.003

Centre for Agriculture and Bioscience International (CABI). (2021a). Crop Protection Compendium. https://www.cabi.org/cpc

Centre for Agriculture and Bioscience International (CABI). (2021b). Invasive Species Compendium. https://www.cabi.org/isc/

Christensen, J. H., Hewitson, B., Busuioc, A., Chen, A., Gao, X., Held, I., Jones, R., Kolli, R. K., Kwon, W.-T., Laprise, R., Rueda, V. M., Mearns, L., Menéndez, C. G., Räisänen, J., Rinke, A., Sarr, A., \& Whetton, P. (2007). 2007: Regional Climate Projections. In M. T. and H. L. M. Solomon, S., D. Qin, M. Manning, Z. Chen, M. Marquis, K.B. Averyt (Ed.), Climate Change 2007: The Physical Science Basis. Contribution of Working Group I to the Fourth Assessment Report of the Intergovernmental Panel on Climate Change. Cambridge University Press. https://doi.org/10.1007/978-81-322-1967-5_4

Cobos, M. E., Townsend Peterson, A., Barve, N., \& Osorio-Olvera, L. (2019). kuenm: An R package for detailed development of ecological niche models using Maxent. PeerJ. https://doi.org/10.7717/peerj.6281

Commonwealth Scientific and Industrial Research Organisation (CSIRO). (2021). An agri-food system innovation in Kenya? Will smallholders be the winners? https://research.csiro.au/foodglobalsecurity/an-agri-food-systeminnovation-in-kenya-will-smallholders-be-the-winners/

Cugala, D., \& Omwega, C. O. (2001). Cereal stemborer distribution and abundance, and introduction and establishment of Cotesia flavipes Cameron (Hymenoptera: Braconidae) in Mozambique. International Journal of Insect Science, 21(4), 281-287. https://doi.org/https://doi.org/10.1017/S1742758400008365

De Groote, H. (2002). Maize yield losses from stemborers in Kenya. Insect Science and Its Application, 22(2), 89-96. https://doi.org/10.1017/s1742758400015162

Dejen, A., Getu, E., Azerefegne, F., \& Ayalew, A. (2013). Distribution and extent of Cotesia flavipes Cameron (Hymenoptera: Braconidae) Parasitism in Northeastern Ethiopia. International Journal of Insect Science, 5, 9-19. https://doi.org/10.4137/ijis.s11009

Elith, J., Phillips, S. J., Hastie, T., Dudík, M., Chee, Y. E., \& Yates, C. J. (2010). A statistical explanation of MaxEnt for ecologists. Diversity and Distributions, 17(1), 43-57. https://doi.org/10.1111/j.1472-4642.2010.00725.x 
FAO, IFAD, UNICEF, WFP, \& WHO. (2020). The State of Food Security and Nutrition in the World 2020. Transforming food systems for affordable healthy diets. FAO. https://doi.org/10.4060/ca9692en

Fick, S. E., \& Hijmans, R. J. (2017). WorldClim 2: new 1-km spatial resolution climate surfaces for global land areas. International Journal of Climatology, 37(12), 4302-4315. https://doi.org/10.1002/joc.5086

Food and Agriculture Organization of the United Nations (FAO). (2021a). FAO Term Portal. http://www.fao.org/faoterm

Food and Agriculture Organization of the United Nations (FAO). (2021b). FAOSTAT data. FAOSTAT Data. http://www.fao.org/faostat/en/\#data

Food and Agriculture Organization of the United Nations (FAO). (2021c). Pesticides indicators. http://www.fao.org/faostat/en/\#data/EP/visualize

Fourcade, Y., Engler, J. O., Rödder, D., \& Secondi, J. (2014). Mapping Species Distributions with MAXENT Using a Geographically Biased Sample of Presence Data: A Performance Assessment of Methods for Correcting Sampling Bias. PLoS ONE, 9(5). https://doi.org/10.1371/journal.pone.0097122

Franklin, J. (2010). Mapping Species Distributions: Spatial Inference and Prediction (Ecology, Biodiversity and Conservation). Cambridge University Press. https://doi.org/doi:10.1017/CBO9780511810602

Giorgi, F. (2019). Thirty Years of Regional Climate Modeling : Where Are We and Where Are We Going next? Journal of Geophysical Research : Atmospheres. Journal of Geophysical Research: Atmospheres, 124, 56965723. https://doi.org/10.1029/2018JD030094

Godefroid, M., Meurisse, N., Groenen, F., Kerdelhué, C., \& Rossi, J. P. (2020). Current and future distribution of the invasive oak processionary moth. Biological Invasions, 22, 523-534. https://doi.org/10.1007/s10530-019-02108-4

Goergen, G., Kumar, P. L., Sankung, S. B., Togola, A., \& Tamò, M. (2016). First report of outbreaks of the fall armyworm spodoptera frugiperda (J E Smith) (Lepidoptera, Noctuidae), a new alien invasive pest in West and Central Africa. PLoS ONE, 11(10). https://doi.org/10.1371/journal.pone.0165632

Goftishu, M., Assefa, Y., Niba, A., \& Fininsa, C. (2017). Cereal stem borer management practices in subsistence farms of eastern Ethiopia. International Journal of Pest Management, 63(4), 289-298. https://doi.org/10.1080/09670874.2016.1258500

Haggblade, S., Diarra, A., \& Traoré, A. (2021). Regulating agricultural intensification: Lessons from West Africa's rapidly growing pesticide markets. Development Policy Review. https://doi.org/10.1111/dpr.12545 
Hailu, G., Niassy, S., Bässler, T., Ochatum, N., Studer, C., Salifu, D., Agbodzavu, M. K., Khan, Z. R., Midega, C., \& Subramanian, S. (2021). Could fall armyworm, Spodoptera frugiperda (J. E. Smith) invasion in Africa contribute to the displacement of cereal stemborers in maize and sorghum cropping systems. International Journal of Tropical Insect Science, 41, 1753-1762.

Intergovernmental Panel on Climate Change (IPCC). (2014). Climate Change 2014: Synthesis Report. Contribution of Working Groups I, II and III to the Fifth Assessment Report of the Intergovernmental Panel on Climate Change.

Intergovernmental Panel on Climate Change (IPCC). (2019). Summary for Policymakers. In J. M. P.R. Shukla, J. Skea, E. Calvo Buendia, V. Masson-Delmotte, H.-O. Pörtner, D. C. Roberts, P. Zhai, R. Slade, S. Connors, R. van Diemen, M. Ferrat, E. Haughey, S. Luz, S. Neogi, M. Pathak, J. Petzold, J. Portugal Pereira, P. Vyas, E. Huntley, K. Kissick, M (Ed.), Climate Change and Land: an IPCC special report on climate change, desertification, land degradation, sustainable land management, food security, and greenhouse gas fluxes in terrestrial ecosystems.

International Food Policy Research Institute (IFPRI). (2016). Agricultural productivity in Africa: Trends, patterns, and determinants (S. Benin (ed.)). IFPRI. https://doi.org/http://dx.doi.org/10.2499/9780896298811

International Food Policy Research Institute (IFPRI). (2020). Spatially-Disaggregated Crop Production Statistics Data in Africa South of the Sahara for 2017. https://doi.org/https://doi.org/10.7910/DVN/FSSKBW

International Fund for Agricultural Development (IFAD). (2017). Sorghum - a new hope in dry times. https://www.ifad.org/fr/web/latest/-/story/sorghum-a-new-hope-in-dry-times

International Institute of Tropical Agriculture (IITA). (2021). Maize. https://www.iita.org/cropsnew/maize/ International Labour Organization (ILO). (2021). ILOSTAT. https://ilostat.ilo.org/data/country-profiles/

Jones, P. G., \& Thornton, P. K. (2003). The potential impacts of climate change on maize production in Africa and Latin America in 2055. Global Environmental Change, 13(1), 51-59. https://doi.org/10.1016/S09593780(02)00090-0

Kaiser, L., Dupas, S., Branca, A., Herniou, E. A., Clarke, C. W., Capdevielle Dulac, C., Obonyo, J., Benoist, R., Gauthier, J., Calatayud, P. A., Silvain, J. F., \& Le Ru, B. P. (2017). The Cotesia sesamiae story: insight into hostrange evolution in a Hymenoptera parasitoid and implication for its use in biological control programs. Genetica, 145(6), 455-468. https://doi.org/10.1007/s10709-017-9989-3

Kamau, J. W., Stellmacher, T., Biber-Freudenberger, L., \& Borgemeister, C. (2018). Organic and conventional agriculture in Kenya: A typology of smallholder farms in Kajiado and Murang'a counties. Journal of Rural 
Karungi, J., Kyamanywa, S., Adipala, E., \& Erbaugh, M. (2011). Pesticide Utilisation, Regulation and Future Prospects in Small Scale Horticultural Crop Production Systems in a Developing Country. In Pesticides in the Modern World - Pesticides Use and Management. https://doi.org/10.5772/17170

Kfir, R., Overholt, W. A., Khan, Z. R., \& Polaszek, A. (2002). Biology and management of economically important lepidopteran cereal stem borers in Africa. Annual Review of Entomology, 47(1), 701-731. https://doi.org/https://doi.org/10.1146/annurev.ento.47.091201.145254

Ladányi, M., \& Horváth, L. (2010). A review of the potential climate change impact on insect populations - general and agricultural aspects. Applied Ecology and Environmental Research, 8(2), 143-152. https://doi.org/10.15666/aeer/0802_143151

Lantschner, M. V., de la Vega, G., \& Corley, J. C. (2018). Predicting the distribution of harmful species and their natural enemies in agricultural, livestock and forestry systems: An overview. International Journal of Pest Management, 65(3), 190-206. https://doi.org/https://doi.org/10.1080/09670874.2018.1533664

Lehmann, P., Ammunét, T., Barton, M., Battisti, A., Eigenbrode, S. D., Jepsen, J. U., Kalinkat, G., Neuvonen, S., Niemelä, P., Terblanche, J. S., Økland, B., \& Björkman, C. (2020). Complex responses of global insect pests to climate warming. Frontiers in Ecology and the Environment, 18(3), 141-150. https://doi.org/10.1002/fee.2160

Luhunga, P. M. (2017). Assessment of the impacts of climate change on maize production in the southern and western highlands sub-agro ecological Zones of Tanzania. Frontiers in Environmental Science, 5(51). https://doi.org/10.3389/fenvs.2017.00051

Merow, C., Smith, M. J., \& Silander, J. A. (2013). A practical guide to MaxEnt for modeling species' distributions: What it does, and why inputs and settings matter. Ecography, 36, 1058-1069. https://doi.org/https://doi.org/10.1111/j.1600-0587.2013.07872.x

Morales, N. S., Fernández, I. C., \& Baca-González, V. (2017). MaxEnt's parameter configuration and small samples: Are we paying attention to recommendations? A systematic review. PeerJ. https://doi.org/https://doi.org/10.7717/peerj.3093

Morton, J. F. (2007). The impact of climate change on smallholder and subsistence agriculture. Proceedings of the National Academy of Sciences of the United States of America, 104(50), 19680-19685. https://doi.org/10.1073/pnas.0701855104 
Mutamiswa, R., Chidawanyika, F., \& Nyamukondiwa, C. (2017). Dominance of spotted stemborer Chilo partellus Swinhoe (Lepidoptera: Crambidae) over indigenous stemborer species in Africa's changing climates: ecological and thermal biology perspectives. Agricultural and Forest Entomology, 19, 344-356. https://doi.org/10.1111/afe.12217

Mwalusepo, S., Tonnang, H. E. Z., Massawe, E. S., Okuku, G. O., Khadioli, N., Johansson, T., Calatayud, P. A., \& Le Ru, B. P. (2015). Predicting the impact of temperature change on the future distribution of maize stem borers and their natural enemies along East African mountain gradients using phenology models. PLoS ONE, 10(6). https://doi.org/10.1371/journal.pone.0130427

Naidoo, S., London, L., Rother, H. A., Burdorf, A., Naidoo, R. N., \& Kromhout, H. (2010). Pesticide safety training and practices in women working in small-scale agriculture in South Africa. Occupational and Environmental Medicine, 67, 823-828. https://doi.org/10.1136/oem.2010.055863

Negatu, B., Dugassa, S., \& Mekonnen, Y. (2021). Environmental and Health Risks of Pesticide Use in Ethiopia. Journal of Health and Pollution, 11(30). https://doi.org/10.5696/2156-9614-11.30.210601

Nsami, E., Pallangyo, B., Mgoo, V., \& Omwega, C. O. (2001). Distribution and species composition of cereal stemborers in the eastern zone of Tanzania. International Journal of Insect Science, 21(4), 347-351. https://doi.org/10.1017/S1742758400008444

Oerke, E. C. (2006). Crop losses to pests. Journal of Agricultural Science, 144, 31-43. https://doi.org/10.1017/S0021859605005708

Omwega, C. O., Muchugu, E., Overholt, W. A., \& Schulthess, F. (2006). Release and establishment of Cotesia flavipes Cameron (Hymenoptera: Braconidae) an exotic parasitoid of Chilo partellus (Swinhoe) (Lepidoptera: Crambidae) in East and Southern Africa. International Journal of Entomology, 42(3-4), 511-517. https://doi.org/https://doi.org/10.1080/00379271.2006.10697486

Overholt, W. A., Omwega, C. O., Mbapila, J., Sallam, M. N., \& Ofomata, V. (1997). A review of the introduction and establishment of Cotesia flavipes Cameron in East Africa for biological control of cereal stemborers. Insect Science and Its Application, 17(1), 79-88. https://doi.org/https://doi.org/10.1017/S1742758400022190

Phillips, S. J. (2017). A Brief Tutorial on Maxent. http://biodiversityinformatics.amnh.org/open_source/maxent/

Phillips, S. J., Anderson, R. P., \& Schapire, R. E. (2006). Maximum entropy modeling of species geographic distributions. Ecological Modelling, 190, 231-259. https://doi.org/10.1016/j.ecolmodel.2005.03.026 
Phillips, S. J., Dudík, M., Elith, J., Graham, C. H., Lehmann, A., Leathwick, J., \& Ferrier, S. (2009). Sample selection bias and presence-only distribution models: Implications for background and pseudo-absence data. Ecological Applications, 19(1), 181-197. https://doi.org/10.1890/07-2153.1

Radosavljevic, A., \& Anderson, R. P. (2014). Making better Maxent models of species distributions: Complexity, overfitting and evaluation. Journal of Biogeography, 41, 629-643. https://doi.org/https://doi.org/10.1111/jbi.12227

Riahi, K., Van Vuuren, D. P., Kriegler, E., \& O’Neill, B. (2016). The Shared Socio-Economic Pathways (SSPs): An Overview.

Salami, A., Kamara, A. B., \& Brixiova, Z. (2010). Smallholder Agriculture in East Africa: Trends, Constraints and Opportunities. (Issue Working Papers Series N 105 African Development Bank). https://doi.org/10.1111/j.1467937X.2007.00447.x

Schreinemachers, P., \& Tipraqsa, P. (2012). Agricultural pesticides and land use intensification in high, middle and low income countries. Food Policy, 37(6), 616-626. https://doi.org/10.1016/j.foodpol.2012.06.003

Skendžić, S., Zovko, M., Živković, I. P., Lešić, V., \& Lemić, D. (2021). The impact of climate change on agricultural insect pests. Insects, 12(440). https://doi.org/https://doi.org/10.3390/ insects12050440

Snyder, J., Cairns Smart, J., Goeb, J., \& Tschirley, D. (2018). Pesticide use in Sub-Saharan Africa: Estimates, Projections, and Implications in the Context of Food System Transformation.

Sokame, M., Musyoka, B., Obonyo, J., Rebaudo, F., Abdel-rahman, E. M., Subramanian, S., Kilalo, D. C., Juma, G., \& Calatayud, P. (2021). Impact of an Exotic Invasive Pest, Spodoptera frugiperda (Lepidoptera : Noctuidae), on Resident Communities of Pest and Natural Enemies in Maize Fields in Kenya. Agronomy 2021, 11(1074). https://doi.org/https://doi.org/10.3390/ agronomy11061074

Stange, E. E., \& Ayres, M. P. (2010). Climate Change Impacts: Insects. In Encyclopedia of Life Sciences (ELS). John Wiley \& Sons, Ltd. https://doi.org/https://doi.org/10.1002/9780470015902.a0022555

Sundström, J. F., Albihn, A., Boqvist, S., Ljungvall, K., Marstorp, H., Martiin, C., Nyberg, K., Vågsholm, I., Yuen, J., \& Magnusson, U. (2014). Future threats to agricultural food production posed by environmental degradation, climate change, and animal and plant diseases - a risk analysis in three economic and climate settings. Food Security, 6(2), 201-215. https://doi.org/10.1007/s12571-014-0331-y

Tamiru, A., Getu, E., \& Jembere, B. (2007). Role of some ecological factors for an altitudinal expansion of spotted stem 
borer, Chilo partellus (Swinhoe) (Lepidoptera: Crambidae). SINET: Ethiopian Journal of Science, 30(1), 71-76. https://doi.org/10.4314/sinet.v30i1.18285

Thomas, K. J. A., \& Zuberi, T. (n.d.). Demographic Change, the IMPACT Model, and Food Security in Sub-Saharan Africa (No. 2012-003).

Thomson, L. J., Macfadyen, S., \& Hoffmann, A. A. (2010). Predicting the effects of climate change on natural enemies of agricultural pests. Biological Control, 52(3), 296-306. https://doi.org/10.1016/j.biocontrol.2009.01.022

Thornton, P. K., Ericksen, P. J., Herrero, M., \& Challinor, A. J. (2014). Climate variability and vulnerability to climate change: A review. Global Change Biology, 20(11), 3313-3328. https://doi.org/10.1111/gcb.12581

Tito, R., Vasconcelos, H. L., \& Feeley, K. J. (2018). Global climate change increases risk of crop yield losses and food insecurity in the tropical Andes. Global Change Biology, 24, e592-e602. https://doi.org/10.1111/gcb.13959

Tsimbiri, P. F., Moturi, W. N., Sawe, J., Henley, P., \& Bend, J. R. (2015). Health Impact of Pesticides on Residents and Horticultural Workers in the Lake Naivasha Region, Kenya. Occupational Diseases and Environmental Medicine, 3, 24-34. https://doi.org/10.4236/odem.2015.32004

United Nations Department of Economic and Social Affairs (UN DESA). (2020). World Economic Situation and Prospects 2020. https:/www.un.org/development/desa/dpad/wp-content/uploads/sites/45/WESP2020_Annex.pdf

United Nations Department of Economic and Social Affairs (UN DESA) Population Division. (2019). World Population Prospects 2019: Highlights. https://population.un.org/wpp/Publications/Files/WPP2019_Highlights.pdf

United Nations Development Programme (UNDP), United Republic of Tanzania (URT), \& Economic and Social Research Foundation (ESRF). (2018). Tanzania Human Development Report 2017: Social Policy in the Context of Economic Transformation. ESRF. http://www.esrf.or.tz/docs/thdr2017launch.pdf

Urvois, T., Auger-Rozenberg, M. A., Roques, A., Rossi, J. P., \& Kerdelhue, C. (2021). Climate change impact on the potential geographical distribution of two invading Xylosandrus ambrosia beetles. Scientific Reports, 11(1339), 1-11. https://doi.org/10.1038/s41598-020-80157-9

Williamson, S., Ball, A., \& Pretty, J. (2008). Trends in pesticide use and drivers for safer pest management in four African countries. Crop Protection, 27, 1327-1334. https://doi.org/10.1016/j.cropro.2008.04.006

World Bank. (2021). World Development Indicators. https://databank.worldbank.org/reports.aspx?source=WorldDevelopment-Indicators 
696 World Meteorological Organization (WMO). (2019). State of the Climate in Africa 2019 (Issue 1253). WMO.

697 Youdeowei, A. (1989). Major arthropod pests of food and industrial crops of Africa and their economic importance. In 698 H. R. Yaninek, J.S., Herren (Ed.), Biological Control: A Sustainable Solution to Crop Pest Problems in Africa 699 (pp. 31-50). IITA.

700 
Figures
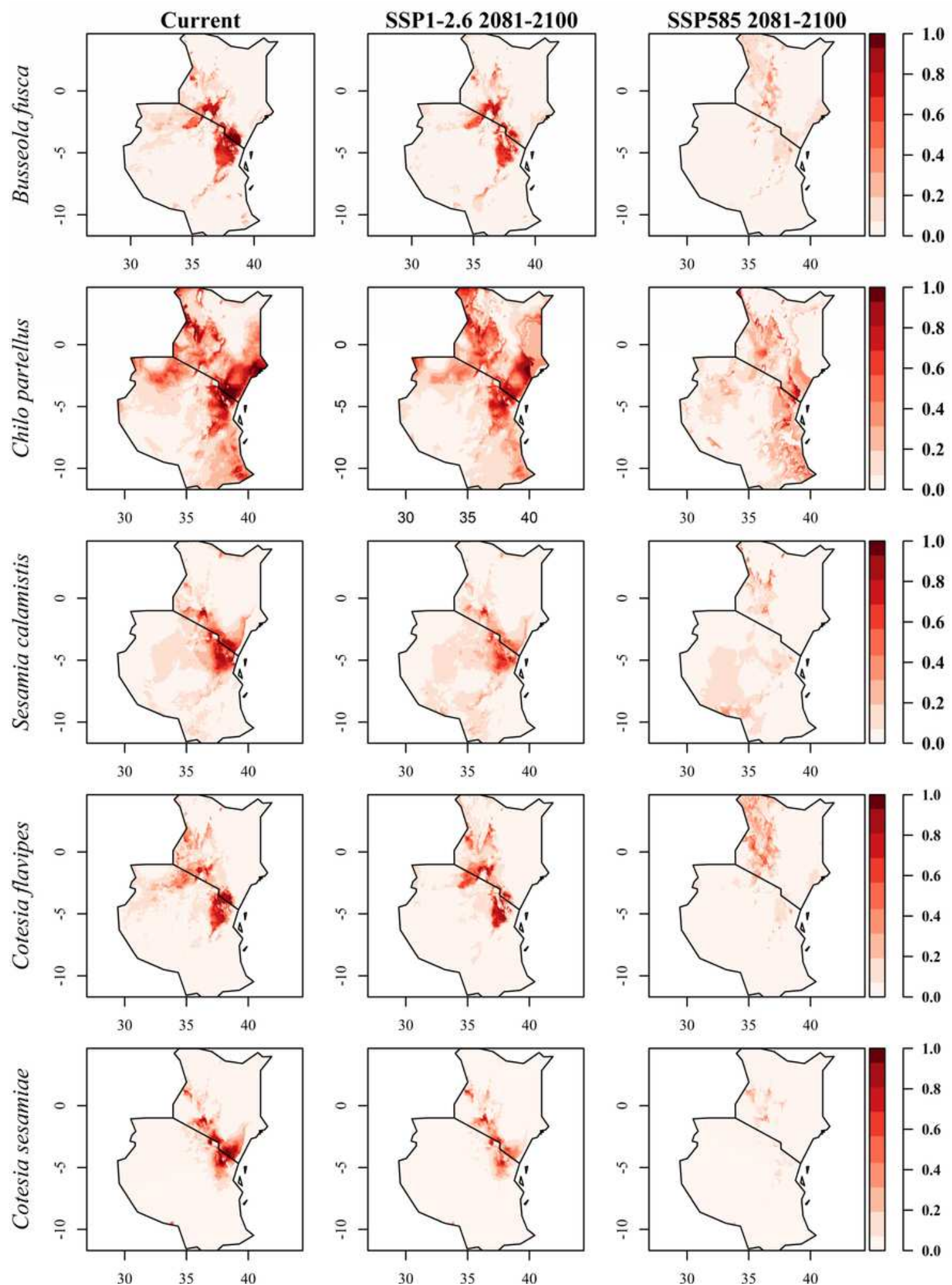

Figure 1

Probability of habitat suitability under current climatic conditions and in 2081-2100 for SSP1-2.6 and SSP5-8.5 calculated as multi-model average from GCMs CanESM5, CNRM-CM6-1 and MIROC6. Probability of habitat suitability ranges between 0 (low probability of suitable habitat) and 1 (perfectly 
suitable habitat). Grid cells with great suitability carry high probability values and are displayed in dark red, whereas cells with low suitability show low probability values and are colored in lighter red and white
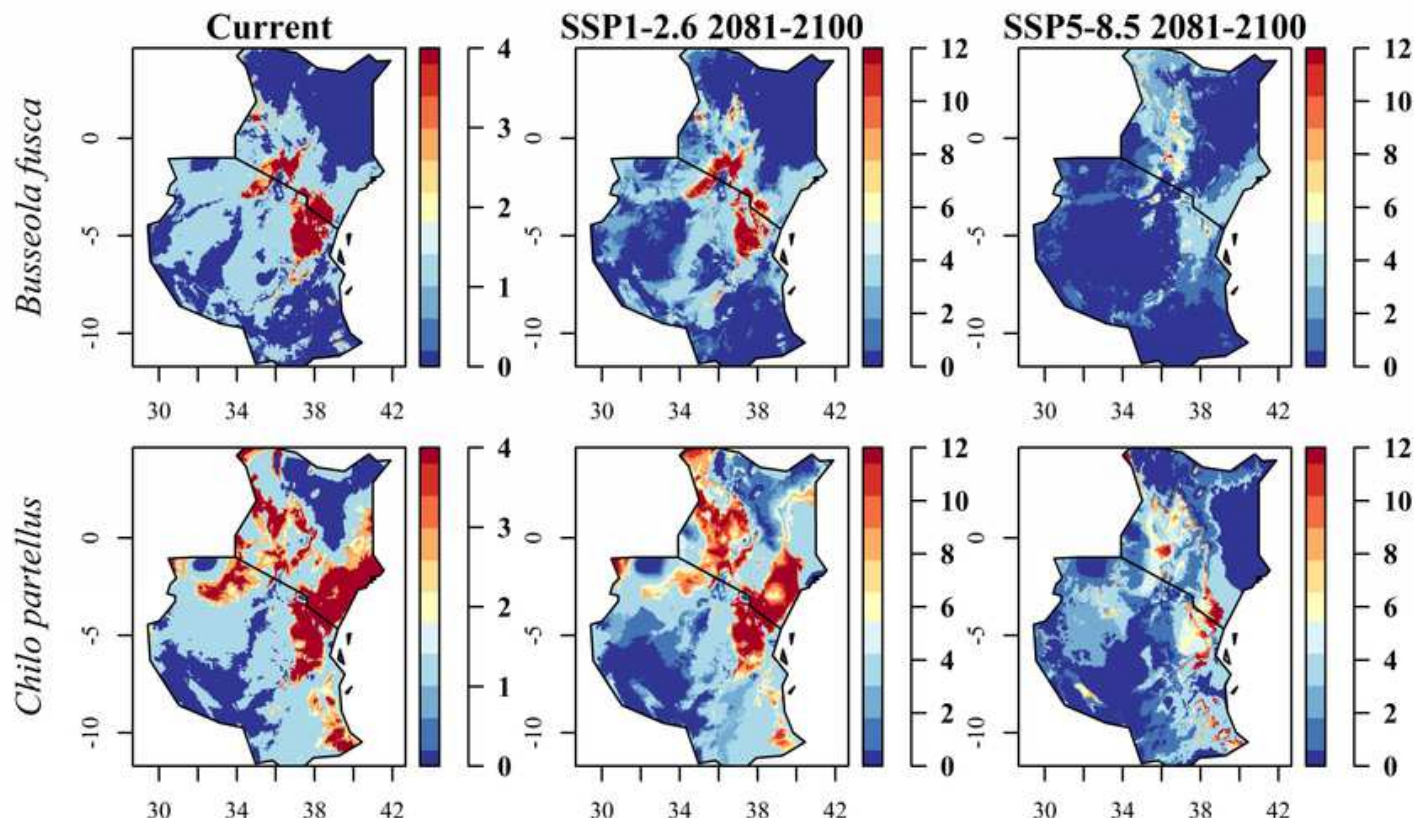

$\begin{array}{llll}30 & 34 & 38 & 42\end{array}$
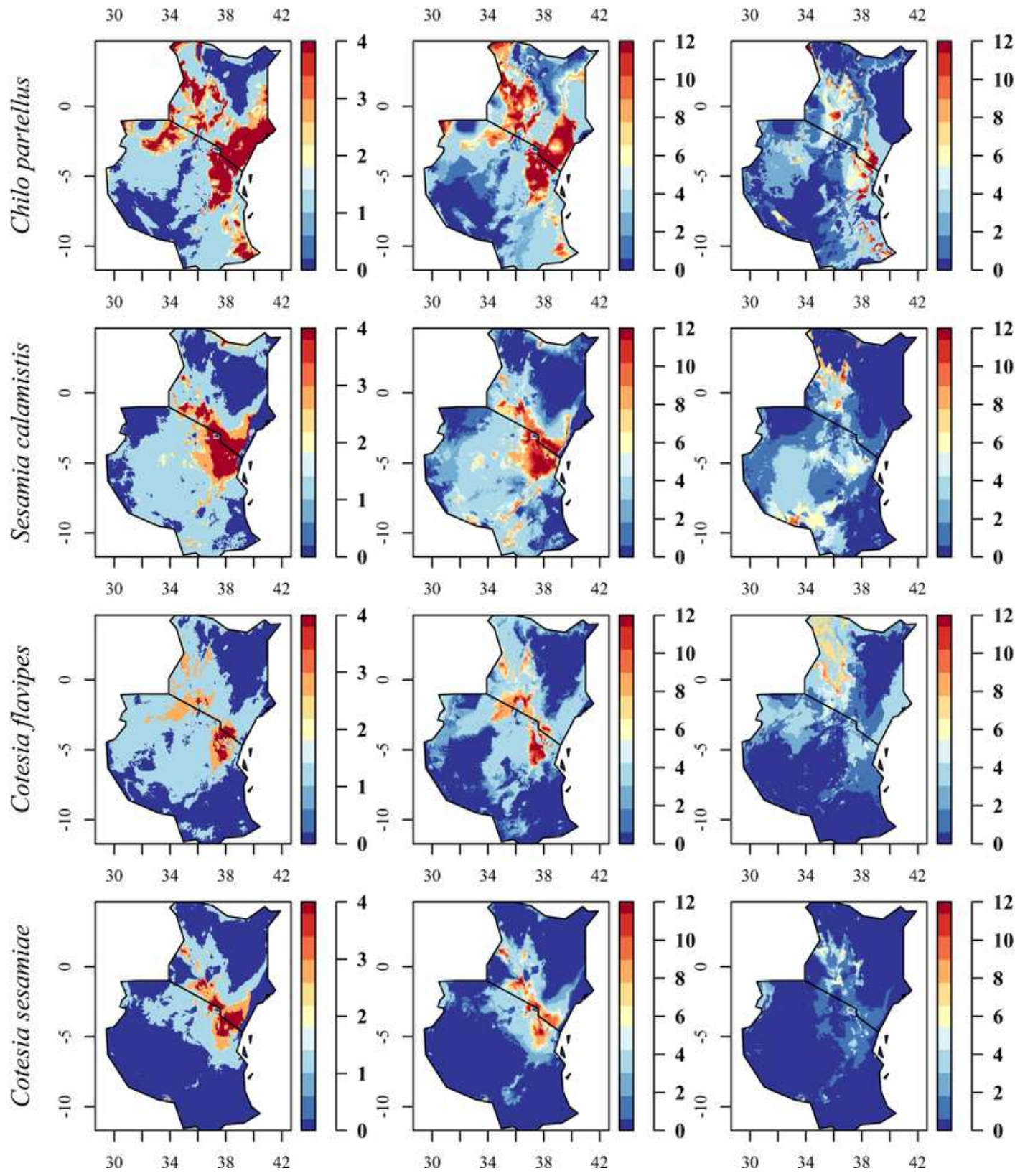

Figure 2

Sum of 4 binary range maps (current distribution) and 12 binary range maps (future distribution) obtained by application of 4 threshold levels, with each binary layer showing either species presence (1) or absence (0). Predicted species distribution under current climatic conditions and for pathways SSP1- 
2.6 and SSP5-8.5 for period 2081-2100. Grid cells where predicted species presence is likely are colored in red and orange, whereas grid cells where presence is less likely are colored in blue
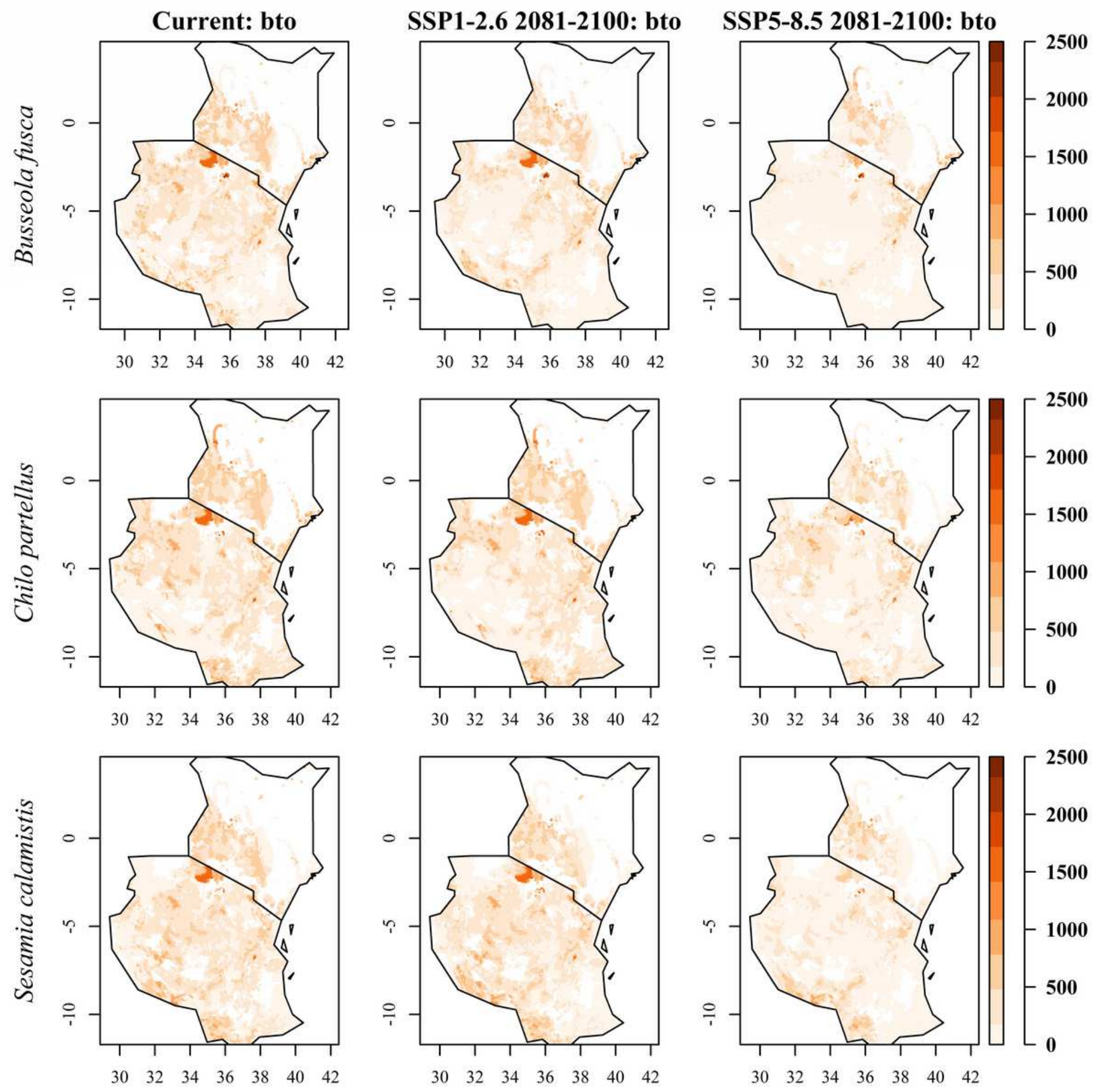

Figure 3

Predicted mean maize yield losses (in $\mathrm{kg} / \mathrm{ha}$ ) by the stem borers B. fusca, C. partellus and S. calamistis under current climatic conditions and in 2081-2100 for SSP1-2.6 and SSP5-8.5 for suitability threshold bto. Grid cells with high predicted yield losses are colored in darker orange to brown, whereas cells where maize yield losses by the species are low are colored in lighter orange and white 

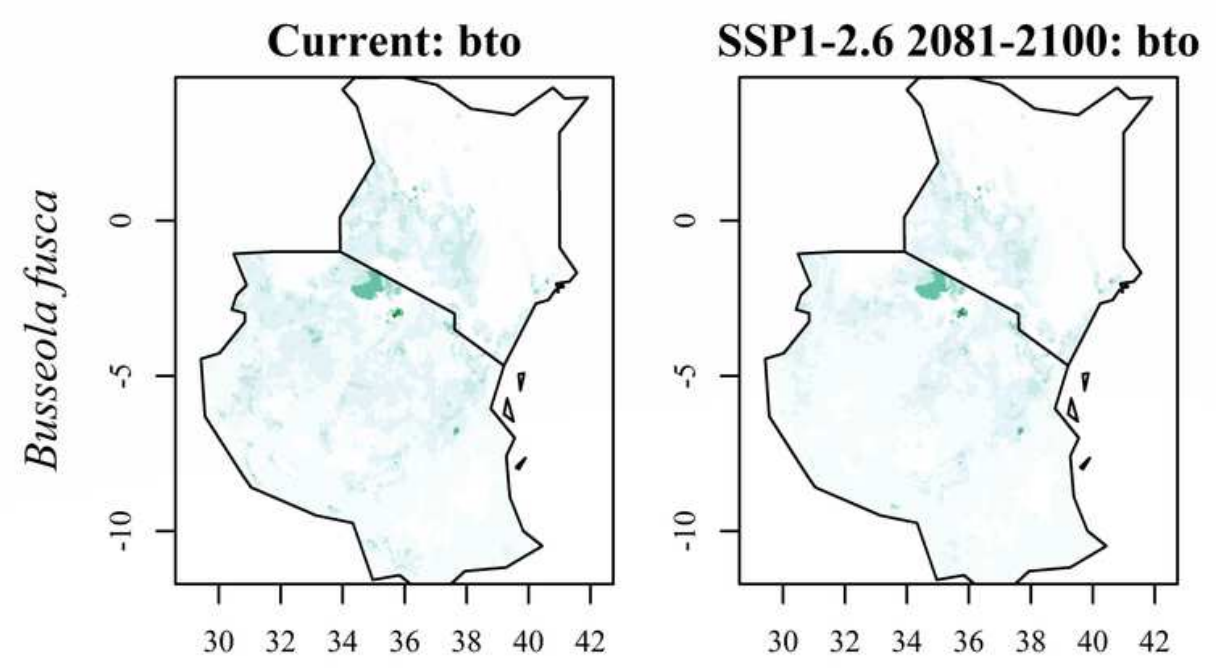

SSP5-8.5 2081-2100: bto
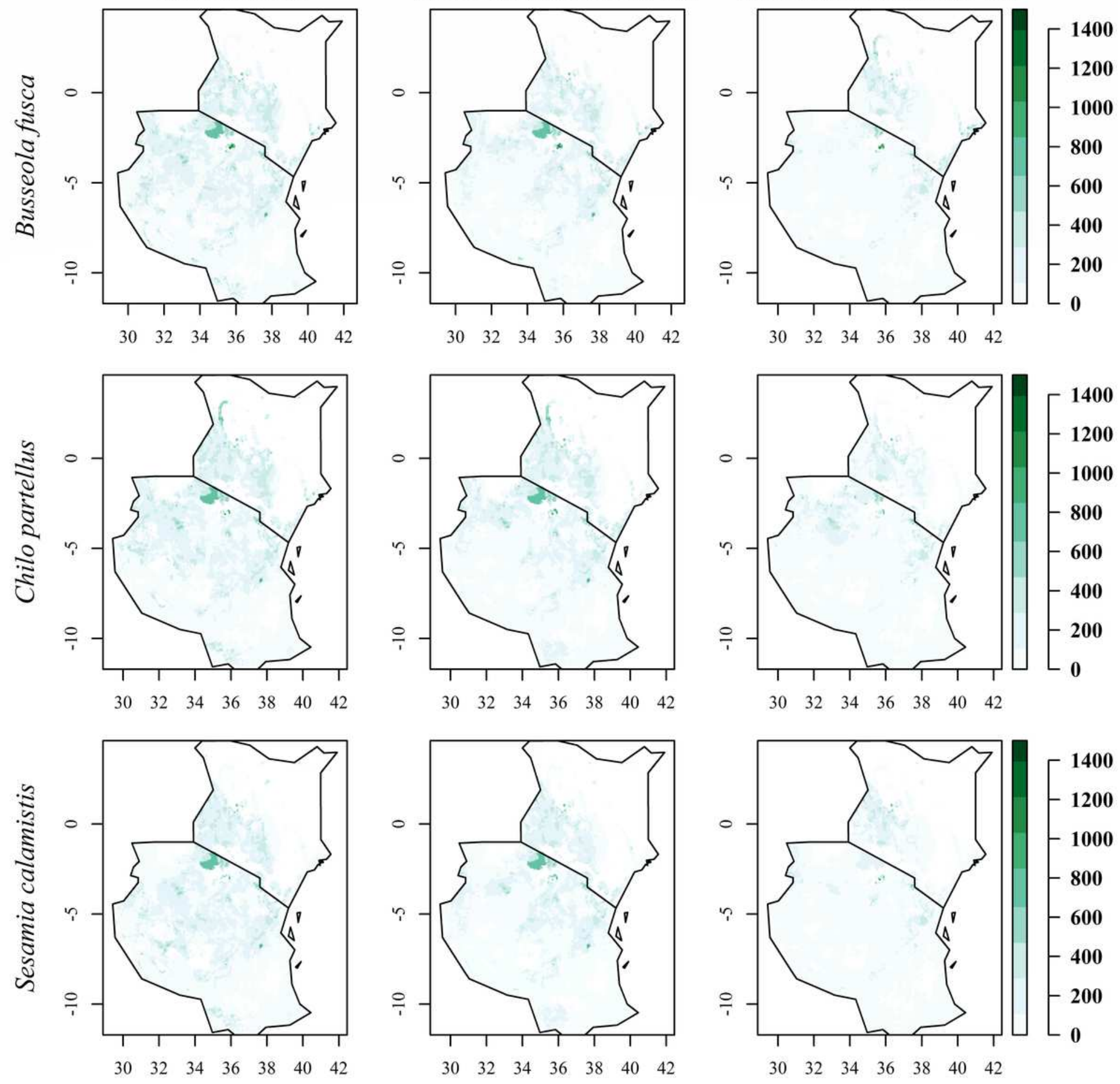

Figure 4

Predicted mean reduction of maize yield losses (in $\mathrm{kg} / \mathrm{ha}$ ) by B. fusca, C. partellus and S. calamistis through use of C. flavipes under current climatic conditions and in 2081-2100 for SSP1-2.6 and SSP58.5 for suitability threshold bto. Grid cells where parasitoid application significantly reduces the amount of maize yield losses caused by the stem borer are colored in darker green, whereas cells with lower predicted reduction of maize yield losses are colored in lighter green and white 

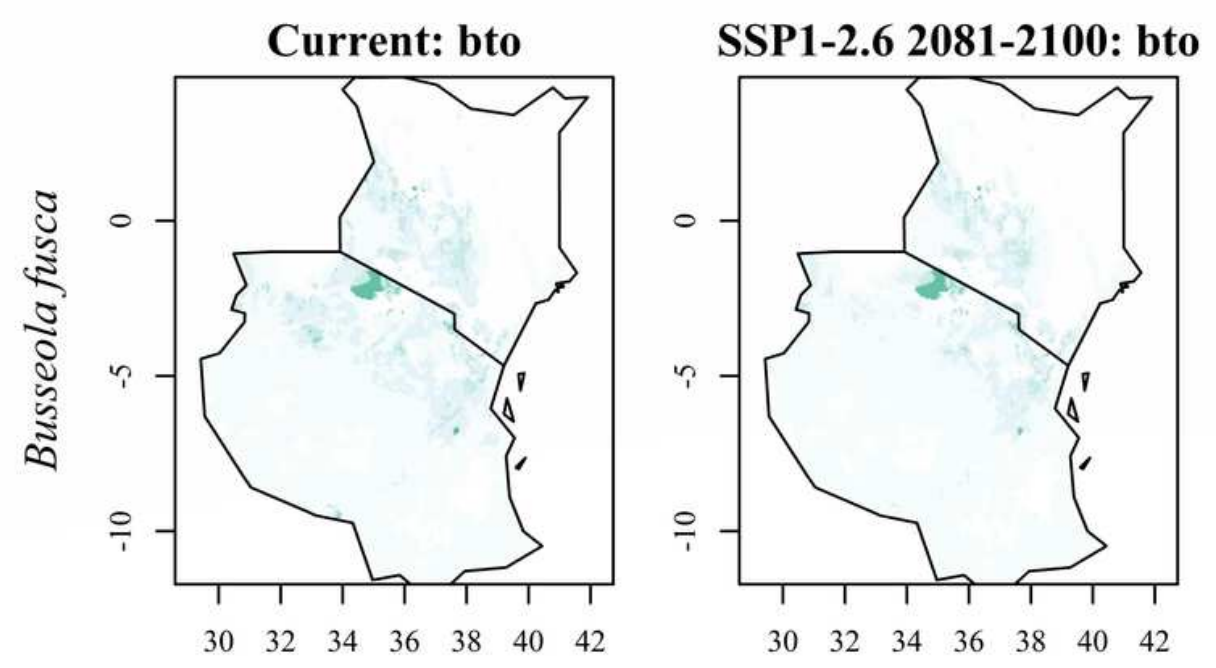

SSP5-8.5 2081-2100: bto
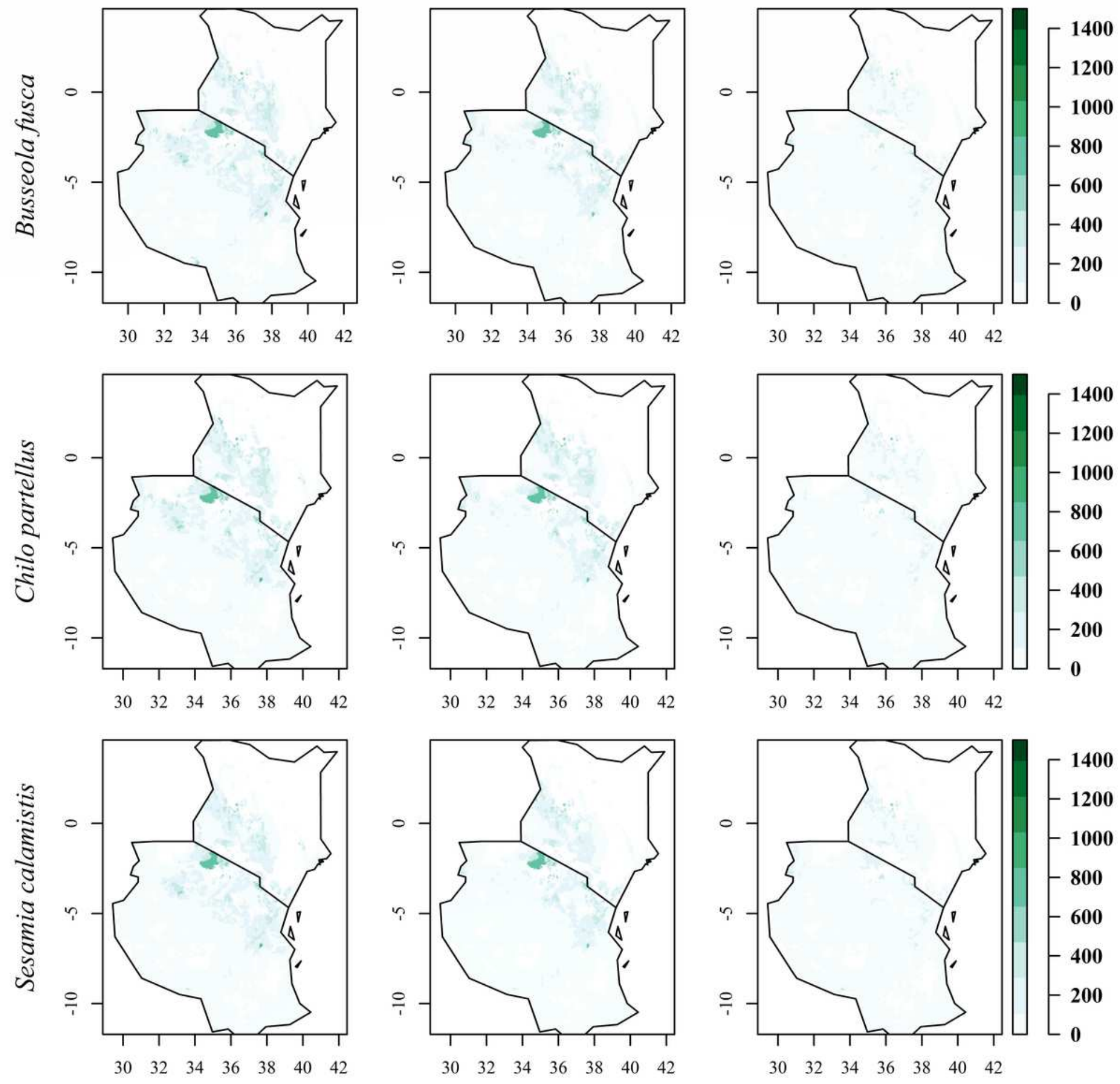

Figure 5

Predicted mean reduction of maize yield losses (in $\mathrm{kg} / \mathrm{ha}$ ) by B. fusca, C. partellus and S. calamistis through use of C. sesamiae under current climatic conditions and in 2081-2100 for SSP1-2.6 and SSP58.5 for suitability threshold bto. Grid cells where parasitoid application significantly reduces the amount of maize yield losses caused by the stem borer are colored in darker green, whereas cells with lower predicted reduction of maize yield losses are colored in lighter green and white 


\section{Supplementary Files}

This is a list of supplementary files associated with this preprint. Click to download.

- 10Distribution.docx

- 11YieldLosses.docx

- 12YieldLossReduction.docx

-1PresencesBusseolafusca.csv

- 1PresencesChilopartellus.csv

- 1PresencesCotesiaflavipes.csv

- 1PresencesCotesiasesamiae.csv

- 1PresencesSesamiacalamistis.csv

- 2PresenceRecordsSources.docx

- 3DescriptionEV.docx

- 4MaizeYields.docx

- 5DistributionPresencePoints.docx

- 60verviewBestModel.docx

- 70verviewAUC.docx

- 8HabitatSuitability.docx

- 9SuitabilityThresholds.docx 